\title{
Introduction to Thematic Section on Interpreting Research
}

The present thematic section of Hermes takes up various aspects of current interpreting research. Daniel Gile and Akira Mizuno review current trends within the field, seen from European and Japanese perspectives, respectively. Franz Pöchhacker, Gun-Viol Vik-Tuovinen, Anne Schjoldager, Friedel Dubslaff, and Cecilia Wadensjö present and discuss their own empirical work. Most contributors are "practisearchers", ie practising interpreters who have become involved in research (eg Gile this volume), and most of them are interpreting teachers. Whereas, according to Gile (eg this volume), interpreting scholars previously seemed to base their work on introspection and personal theorization, the scholars in this thematic section on interpreting are agreed to advocate empirical, systematic studies, though their choice of theoretical framework varies considerably.

Daniel Gile (France) reviews recent developments in the interpreting research community. Prospects are generally positive: The scholars from the "liberal arts community", who indulged in introspection and personal theorization, are losing influence, research methodologies are generally more systematic than before, and there is an increasing openness towards interdisciplinary work. However, this definitely does not mean that all is well, as research obstacles are still numerous, and as actual empirical work is still relatively scarce.

Franz Pöchhacker (Austria) discusses theoretical and methodological issues in connection with his own study of professional simultaneous interpreting, recorded at an authentic conference. In his study, Pöchhacker draws on and expands functionalist translation theory, especially Vermeer's Skopos Theory. Thus, his interests lie more with the interpreter's output than with the process. To account for the high complexity involved in determining the purpose - ie skopos - of simultaneous conference interpreting, Pöchhacker introduces the concept of hypertext. Pöchhacker's subjects interpreted English into German. 


\section{2}

Gun-Viol Vik-Tuovinen (Finland) presents the results of an investigation into student performances in simultaneous interpreting at the beginning and the end of their interpreting training. In her analytical evaluation of the performances, she employs a modified version of Kopczynski's (1980 and 1981) model of analysis. The corpus consists of simultaneous interpreting from Finnish into Swedish.

Anne Schjoldager (Denmark) explores the usefulness of the concept of translational norms (Toury 1980) in connection with a project on simultaneous interpreting and translation. Though two professional translators contributed to the corpus, the subjects of the investigation are mainly students. In a product-oriented study, whose basis is a sourcetarget comparison, Schjoldager hypothesizes about translational norms influencing the translational process. The material consists of interpretations and translations between Danish and English.

Drawing on discourse analysis, especially Ariel's (1990) Accessibility Theory, Friedel Dubslaff (Denmark) compares speaker's and interpreters' discourse models in an investigation into simultaneous interpreting performed by advanced student interpreters and professionals in a simulated conference. Using Ariel's Accessibility Scale of referential expressions as an analytical tool, Dubslaff hypothesizes about production conditions in the interpreting process. Dubslaff's subjects interpreted German speeches into Danish.

Whereas other contributors write about simultaneous interpreting, Cecilia Wadensjö (Sweden) deals with dialogue interpreting or community interpreting. As her theoretical framework is sociology and anthropology, especially Goffman's (1981) participation framework, Wadensjö is less interested in the interpreter's task as a translator than in analyzing the interpreter's role as a coordinator of talk. Thus, rather than looking at the interpreter's output in isolation, Wadensjö concentrates on social roles. Her subjects are Swedish state-authorized interpreters of Russian, working in hospitals, police stations and court rooms.

Akira Mizuno (Japan) reviews current research on interpreting in his native country. Though still in its infancy, with numerous obstacles more serious than the ones described by Gile, interpreting research in Japan will probably prosper due to the foundation of the Interpreting 
Research Association of Japan in 1991. Japanese scholars seem particularly interested in interpreting problems caused by syntactic differences between Japanese, an SOV-language, and languages such as English, an SVO-language.

Anne Schjoldager, 19 December 1994 